\title{
The Relation between Knowledge Heterogeneity and Knowledge Innovation Performance of R \& D Team
}

\author{
Rui Yang, Jiaying Yang \\ South China University of Technology, Guangzhou, China \\ Email: 820677124@qq.com
}

Received 26 February 2014; revised 24 March 2014; accepted 23 April 2014

Copyright (C) 2014 by authors and Scientific Research Publishing Inc.

This work is licensed under the Creative Commons Attribution International License (CC BY). http://creativecommons.org/licenses/by/4.0/

(c) (i) Open Access

\begin{abstract}
Using a sample of 252 R \& D teams in Guangzhou, Foshan, Shenzhen, the researcher empirically examines the relationship between knowledge heterogeneity and knowledge innovation performance, the mediating role of knowledge share. Results indicate that knowledge heterogeneity is positively related to knowledge share, the same with knowledge share and knowledge innovation performance. This paper analyzes the results comprehensively and makes recommendations from multiple perspectives including building the knowledge heterogeneous steams, advocating the collaborative spirit, building a knowledge shared platform, improving the organizational structure, and grooming the communication.
\end{abstract}

\section{Keywords}

Developing Team, Knowledge Heterogeneity, Knowledge Share, Knowledge Innovation Performance

\section{Introduction}

Recently, knowledge innovation has emerged as a key determinant of enterprise innovation. In recent years, R \& $\mathrm{D}$ team plays a leading role in enterprise innovation activities. The team members' knowledge stocks are of great differences, which are connected to the team innovation performance. Currently, scholars have taken an interest in team heterogeneity. Most of the related researches analyze team heterogeneity comprehensively, paying attention to team members' age heterogeneity, gender heterogeneity and knowledge heterogeneity [1]. Research focusing on knowledge heterogeneity only is rare. However, the mechanism how knowledge heterogeneity influences team innovation performance is very complicated, which has seldom been tested. What's 
more, team conflict is the most common mediating variable in the existing mechanisms. On the basis of previous researches, this paper investigates the mechanism how knowledge heterogeneity affects team innovation performance through knowledge share, helping enterprises improve the results of knowledge share and team innovation performance.

\section{Issues Raised}

Knowledge is a hybrid which consists of values, related information and structured experiences. R \& D team is a group that is built up by different members. The differences exist in knowledge, experience, ability, and ways of thinking, ideas, habits, personality traits and many other aspects. A basic feature of the group is knowledge heterogeneity.

The concept of knowledge innovation is mentioned, who regards knowledge innovation as a process of promoting enterprises' success and the development of country's economy through the creation, exchange and application of knowledge and the transformation from knowledge to product or service. Gilson examined the relation between knowledge heterogeneity and knowledge innovation performance, finding that comparing with individuals working in a team with low heterogeneity and others working in a team with high heterogeneity have higher creativity.

As the key of knowledge management in organizations [2], knowledge share (Kaser \& Mile, 2002; Li Tao, Wang Bing, 2003) makes competitive advantages for creating knowledge, having great importance in knowledge management [3]. Scholars such as Xie Yongping considers that knowledge share is the process of knowledge exchange between individuals, including the acquisition, absorption, internalization, application of knowledge and some other stages.

Issues related to team heterogeneity have been paid increasing attention to by scholars, leading to an increasing number of relevant papers. Those researches have advanced our understanding of team heterogeneity comprehensively [4]. More specifically, we need a better understanding of knowledge heterogeneity. Although there are some primary ideas about the mechanisms how knowledge heterogeneity affects team innovation performance, few of them have been examined [5]. Moreover, team conflict and team communication play the mediating role in most of the corresponding empirical studies, which lead to different results sometimes. Dang Hongli ascribes the phenomenon to the existence of other potential mediating variables. On this basis, we introduce knowledge share to the model, expecting to find other mediating variable between knowledge heterogeneity and team innovation performance through testing hypotheses.

\section{Theory and Hypotheses}

\subsection{Hypotheses}

\subsubsection{The Relation between Knowledge Heterogeneity and Knowledge Innovation Performance}

Several foreign scholars think that the heterogeneity of a group is positively related to its creativity and the ability of innovation [6], which has been proved clearly in empirical studies (Katz, 2002) [7]. On the base of literature, Jiang Rifu (2007) [8] and other scholars summarized six basic factors in team features influencing team innovation performance, including team vision, team leader, team structure, team mission, team communication and team excitation. Team knowledge heterogeneity is a significant aspect of team heterogeneity, which belongs to the third team structure factor. Cummings indicates that the diversity of team knowledge can positively contribute to the appearance of new knowledge. A team with higher knowledge diversity is easier to acquire external knowledge and create new knowledge. Therefore, the first hypothesis of this research is:

H1: Knowledge heterogeneity is positively related to knowledge innovation performance.

\subsubsection{The Relation between Knowledge Heterogeneity and Knowledge Share}

Knowledge heterogeneity is positively related to knowledge share, which has been examined in pervious empirical studies. Anand and Clarkdefine externality and difference as two dimensions of knowledge structure in relevant researches. Difference refers to the differences of team members' knowledge, which obviously influences the team's ability to integrate team members' knowledge and deal with all kinds of information.

On the other hand, Campion and other scholars think team members' knowledge heterogeneity reflecting on differences in their abilities can affect their satisfaction and communication negatively, leading to more compe- 
tition among team members. Therefore, obvious differences in work experience, skills and relevant knowledge between team members may be not conducive to knowledge share (Lu Xiaojun, Yu Wenzhao, 2005) [9]. Zhang Jian (2008) [10] argues knowledge heterogeneity may constitute an obstacle to organizational learning and obstruct knowledge share when researching knowledge in enterprise technology alliance from the perspective of organizational learning. Considering the factor sharing tendency has been ignored in Zhang Jian and other scholars' researches and its existence among both team members and executives at the beginning of team building, this paper suggest the positive relationship between knowledge heterogeneity and knowledge share. There are different views on divided dimensions of knowledge share. Lin \& Lee divided knowledge share into share attitude, share subjective norms and share behavior controllability while King \& Marks divided it into share frequency and share effort. Considering the influences of Chinese cultural background, this paper divided knowledge share into share quality, collaborative spirit and Miyuki performance referring to Yang Yuhao's research. In particular, share quality refers to the work relevance, accuracy and timeliness of the shared knowledge; Collaborative spirit means colleagues are willing to teach each other new knowledge, solve partners' problems and provide technical guidance; Miyuki performance reflects in the frequency of attending company activities, enthusiasm in collective activities and communication with colleagues. Due to pervious researches, the following hypotheses are proposed.

H2: Knowledge heterogeneity is positively related to knowledge share.

H2a: Knowledge heterogeneity is positively related to share quality.

H2b: Knowledge heterogeneity is positively related to collaborative spirit.

H2c: Knowledge heterogeneity is positively related to Miyuki performance.

\subsubsection{The Relationship between Knowledge Share and Knowledge Innovation Performance}

The relationship between knowledge share and knowledge innovation performance has been validated in many scholars' researches. The promotion of knowledge innovation performance is based on acquisition of knowledge. Knowledge share is a significant approach to acquire knowledge resources through which individual knowledge resource can be transferred to team knowledge resources, promoting the improvement of knowledge innovation performance effectively.

Dang Hongli explained the positive relationship between knowledge share and knowledge innovation from the perspective of social Networking, suggesting that individuals provide their own knowledge and absorb or apply others' simultaneously, forming knowledge flows within the team, contributing to the formation of new knowledge. Chieh also argued the significant effects knowledge share have on organization learning and knowledge creation and its role in promoting the improvement of innovation ability and innovation performance, which is similar to Subramaniam \& Youndt's opinion. In response to the discussion above, this paper suggest:

H3: Knowledge share is positively related to knowledge innovation performance.

H3a: Share quality is positively related to knowledge innovation performance.

H3b: Collaborative spirit is positively related to knowledge innovation performance.

H3c: Miyuki performance is positively related to knowledge innovation performance.

\subsubsection{The Relationship between Knowledge Heterogeneity Knowledge Share and Knowledge Innovation Performance}

Cohen and Levinthal emphasize that individuals with different knowledge structures are able to create new knowledge coupling mode and improve innovation ability at both individual level and team level through knowledge interaction, exerting positive impact on knowledge innovation performance. Wright argues the heterogeneous knowledge belonging to team members can form new levels of knowledge through communication and integration between individuals as well as knowledge share. Smith also suggest that knowledge diversity among team members owing to their different professional backgrounds can provide diversified information which advances team's understanding on what is happening and is conducive to the improvement of both knowledge innovation and decision quality. The impact will be strengthened by temperate interaction and discussion of knowledge within the team. At the same time, exchange and integration of knowledge among team members is helpful to form new knowledge.

In view of literature previously, the following hypotheses are proposed:

H4: Knowledge share mediates the relationship between knowledge heterogeneity and knowledge innovation performance. 
H4a: Share quality mediates the relationship between knowledge heterogeneity and knowledge innovation performance.

H4b: Collaborate spirit mediates the relationship between knowledge heterogeneity and knowledge innovation performance.

H4c: Miyuki performance mediates the relationship between knowledge heterogeneity and knowledge innovation performance.

In conclusion, there are certain theoretical supports about the twenty-two relationship between the three variables needed to examine the mediating role of knowledge share. On the basis, some scholars emphasize that knowledge share plays an important role when knowledge heterogeneity affects knowledge innovation performance. For instance, Jehn suggests that heterogeneous knowledge causes team members' different ways of thinking, different solutions to problems and different discursive patterns, which are conducive to knowledge collision and knowledge share, improving team members' enthusiasm and exciting knowledge creation and knowledge innovation. This paper constructs theoretical model after reviewing the literature as Figure 1.

\subsection{Study Sample and Sampling Procedure}

The data used for our empirical analysis were collected from emprise R\&D teams that engage in biotechnology, application software, online game and communication equipment research and development in Guangzhou, Shenzhen and Foshan. The questionnaires were filled by team leaders. 330 questionnaires were sent when 267 of them were turned finally. The recovery is $80.91 \%$. Moreover, after excluding 15 invalid and incomplete questionnaires, the response rate reduced to $76.36 \%$.

\subsection{Variable Measurement}

\subsubsection{Scale Determination}

Likert scale five dimensions was used in the measurement. In particular:

1) Knowledge heterogeneity: we modified and improved ours. For instance: "Each member of our team has knowledge concerning team project that unknown by others".

2) Knowledge share: In accordance with structured scale for Chinese local emprises put forward by Yang Yuhao, we developed the scale. For instance: "Team members usually share knowledge in simple and understandable way".

3) Knowledge innovation performance: The scale was mainly recommended by Wang Yin (2011) [11] and was microscopically modified basing on researches of Nonaka \& Takeuchi and other scholars. For instance: "We form specific practices and processes to guarantee efficient work".

\subsubsection{Common Method Bias Conformity}

The data came from questionnaires filled out by team leaders, leading to the possibility of common method bias. Therefore, corresponding traditional statistical methods such as test of single factor, Harman has been used to test it during statistics. As shown in Table 1, there were 13 factors whose eigenvalues were not smaller than 1 explaining $64.44 \%$ variation, which proved the inexistence of serious common method bias.

\section{Data Analysis and Hypotheses Testing}

\subsection{The Reliability and Validity of the Measures}

As shown in Table 2, the Cronbach's $\alpha$ coefficients all reached the recommended threshold, being between 0.7 and 0.8 , which meant an ideal level of reliability.

The scale data was evaluated by project analysis such as CTTC test. The CITC values of the tested questions were all above the usual threshold 0.5 while the significant probability was lower than 0.01 . With regard to validity, the KMO values were clearly above the recommended threshold of 0.7. Overall, the scales were suitable for factor analysis. The factor loading of each question was all higher than 0.5 , which allowed us to conclude that the scales for three variables meet requirements.

\subsection{Correlation Analysis}

The paper aims to examine if knowledge share mediate the relationship between knowledge heterogeneity and 


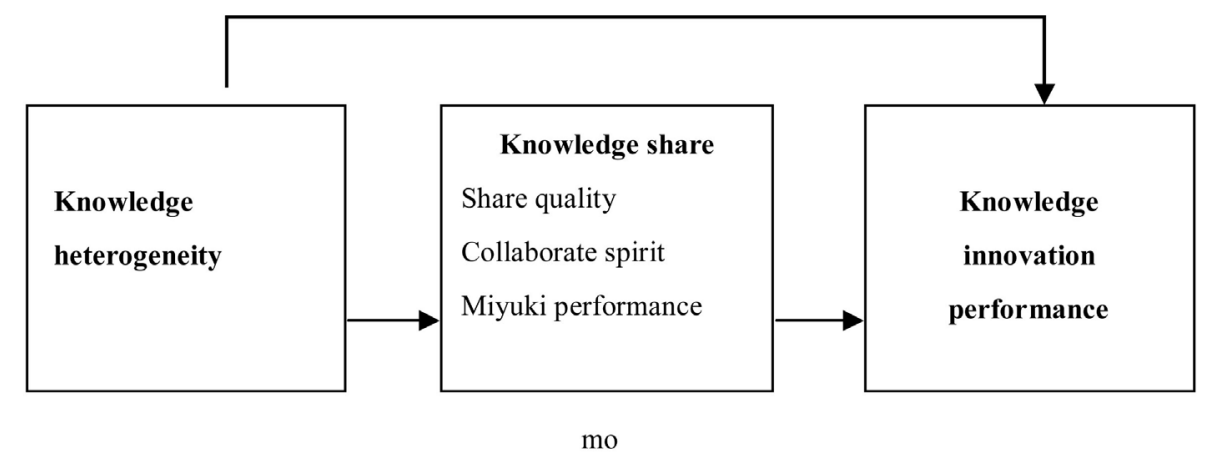

Figure 1. The model of knowledge heterogeneity, knowledge share and knowledge innovation performance.

Table 1. Common method bias conformity.

\begin{tabular}{ccc}
\hline Factor Number & Variance $\%$ & Accumulation \% \\
\hline 1 & 10.813 & 10.813 \\
2 & 7.948 & 18.761 \\
3 & 6.169 & 24.930 \\
4 & 5.261 & 30.191 \\
5 & 4.944 & 35.135 \\
6 & 4.656 & 39.791 \\
7 & 4.401 & 44.192 \\
8 & 3.957 & 48.149 \\
9 & 3.695 & 51.844 \\
10 & 3.466 & 55.310 \\
11 & 3.234 & 58.544 \\
12 & 3.039 & 61.583 \\
13 & 2.858 & 64.440
\end{tabular}

Table 2. The result of Cronbach's $\alpha$.

\begin{tabular}{ccc}
\hline Variable & Cronbach’s $\alpha$ & Variable \\
\hline Knowledge Heterogeneity & 0.770 & Share Quality \\
Collaborative Spirit & 0.762 & Miyuki Performance \\
Knowledge Innovation Performance & 0.769 & \\
\hline
\end{tabular}

knowledge innovation performance. The correlation analysis must be done to investigate the specific circumstances of the linearity in relations between three variables.

As shown in Table 3, knowledge heterogeneity and the other four variables were significantly twenty-two related. In particular, knowledge heterogeneity was related to share quality at the level of 0.05 when the other twenty-two relations were at the level of 0.01 . The correlation coefficients were lower than 0.9 , meaning the inexistence of multicollinearity between variables.

In conclusion, the variables in Table 3 are interdependent instead of independent.

\subsection{Regression Analysis and Intermediation Analysis}

\subsubsection{Regression Analysis}

The result of significant test in the regression analysis using knowledge heterogeneity as independent variable and knowledge innovation performance as dependent variable was 0.000 , suggesting the regression relation between them. On other hand, from Table 4 their regression coefficient was 0.594, proving H1. H2, H2a, H2b, H2c, H3, H3a, H3b, H3c were examined in the same way. 
Table 3. Correlation analysis.

\begin{tabular}{|c|c|c|c|c|c|}
\hline Variable & $\begin{array}{l}\text { Knowledge } \\
\text { heterogeneity }\end{array}$ & Share quality & Collaborative spirit & Miyuki performance & $\begin{array}{c}\text { Knowledge innovation } \\
\text { performance }\end{array}$ \\
\hline Knowledge heterogeneity & 1 & & & & \\
\hline Share quality & $0.396^{* *}$ & 1 & & & \\
\hline $\begin{array}{l}\text { Collaborative } \\
\text { spirit }\end{array}$ & $0.161^{*}$ & $0.170^{* *}$ & 1 & & \\
\hline Miyuki performance & $0.305^{* *}$ & $0.594^{* *}$ & $0.364^{* *}$ & 1 & \\
\hline $\begin{array}{l}\text { Knowledge innovation } \\
\text { performance }\end{array}$ & $0.364^{* *}$ & $0.230^{* *}$ & $0.469^{* *}$ & $0.338^{* *}$ & 1 \\
\hline
\end{tabular}

Ps: Number of samples is $252,{ }^{*}$ means significant at the level of $0.05,{ }^{* *}$ means significant at the level of 0.01 .

\section{Table 4. Regression analysis.}

\begin{tabular}{|c|c|c|c|c|c|}
\hline Item & $\mathrm{R}^{2}$ & B & Standard deviation & $\mathrm{t}$ & Sig \\
\hline Knowledge heterogeneity and knowledge innovation performance & 0.746 & 0.594 & 0.022 & 27.110 & 0.000 \\
\hline Knowledge heterogeneity and knowledge share & 0.550 & 0.407 & 0.023 & 17.485 & 0.000 \\
\hline Knowledge share and knowledge innovation performance & 0.785 & 1.112 & 0.037 & 30.200 & 0.000 \\
\hline Knowledge heterogeneity and share quality & 0.634 & 0.658 & 0.032 & 20.809 & 0.000 \\
\hline Knowledge heterogeneity and collaborative spirit & 0.526 & 0.399 & 0.038 & 15.583 & 0.000 \\
\hline Knowledge heterogeneity and Miyuki performance & 0.497 & 0.461 & 0.029 & 15.716 & 0.000 \\
\hline Share quality and knowledge innovation performance & 0.689 & 0.691 & 0.029 & 23.538 & 0.000 \\
\hline Collaborative spirit and knowledge innovation performance & 0.569 & 0.525 & 0.063 & 15.389 & 0.000 \\
\hline Miyuki performance and knowledge innovation performance & 0.544 & 0.776 & 0.045 & 17.285 & 0.000 \\
\hline
\end{tabular}

As a check for intermediation, we took stepwise regression to observe the diversification of independent variable regression coefficient after adding mediating variable to the regression model, which was the evidence of intermediation and the basis on which we can distinguish between partial intermediation and complete intermediation. If the regression coefficient becomes insignificant from significant, the variable mediates the model fully. Conversely, the intermediation is partial.

\subsubsection{The Confirmatory Test of Variable Discriminant Validity}

At first, we divided the variable with only one factor into three parts randomly (Referring to Wang et al., 2005, the method in p.426 and Kelloway's explanation in pp.135-136, 1998, avoiding that there is only one indicator of the latent variable resulting in the failure to identify the model.) Secondly, we took confirmatory factor analysis using the factors of knowledge heterogeneity, knowledge share and knowledge innovation performance as indicators. Table 5 and Table 6 showed that knowledge heterogeneity, knowledge share and knowledge innovation performance were three different concepts with good discriminant validity, which allowed the structural equation model analysis.

As shown in Figure 2, the path coefficient is 0.77; accounting for the significant impact knowledge heterogeneity has on knowledge innovation performance. Model 2 emphasizes the effects that knowledge heterogeneity has on knowledge share and knowledge share affects knowledge innovation performance significantly. Model 4 used data inspection to examine the mediating role of knowledge share, causing the decrease of path coefficient in model 1 to 0.45 . The partial intermediation has been verified.

It can be seen that knowledge share mediates the relationship between knowledge heterogeneity and knowledge innovation performance partly. The process can also be affected by team communication, team conflict and other variables.

\section{Results and Analysis.}

\subsection{Results}

1) The influences of knowledge heterogeneity on knowledge innovation performance:

Wang Yin and other scholars suggest that low levels of knowledge heterogeneity caused by too much over- 
Table 5. Regression analysis.

\begin{tabular}{ccccccccc}
\hline Model & Factor & $\chi^{2}$ & $\boldsymbol{d f}$ & $\Delta \chi^{2}$ & GFI & RMSEA & CFI & TLI \\
\hline Null model & & 3777.49 & 45 & & & & & \\
Basic model & Three factors: KH; KS; KIP & 260.67 & 32 & & 0.94 & 0.094 & 0.94 & 0.91 \\
Model 1 & Two factors: KH; KS+KIP & 581.59 & 34 & $320.92^{* *}$ & 0.87 & 0.14 & 0.88 & 0.81 \\
Model 2 & Two factors: KH; +KS; KIP & 769.68 & 34 & $509.01^{* *}$ & 0.84 & 0.16 & 0.83 & 0.74 \\
Model 3 & Two factors: KH + KIP; KS; & 996.02 & 34 & $735.35^{* *}$ & 0.80 & 0.19 & 0.77 & 0.66 \\
Model 4 & One factor: KH + KS + KIP & 1230.52 & 35 & $969.85^{* *}$ & 0.77 & 0.21 & 0.73 & 0.59 \\
\hline
\end{tabular}

Table 6. Structural equation model test results.

\begin{tabular}{cccccccc}
\hline Structural equation model & Path coefficient & GFI & RMSEA & CFI & PNFI & TLI \\
\hline $1 . \mathrm{KH} \rightarrow \mathrm{KIP}$ & $0.77^{* *}$ & 0.94 & 0.092 & 0.94 & 0.68 & 0.92 \\
$2 . \mathrm{KH} \rightarrow \mathrm{KS}$ & $0.32^{* *}$ & 0.91 & 0.11 & 0.89 & 0.65 & 0.88 \\
$3 . \mathrm{KS} \rightarrow \mathrm{KIP}$ & $0.16^{*}$ & 0.91 & 0.12 & 0.89 & 0.65 & 0.86 \\
$4 . \mathrm{KH} \rightarrow \mathrm{KS} \rightarrow \mathrm{KIP}$ and $\mathrm{KH} \rightarrow \mathrm{KIP}$ & $0.45^{* *}$ & 0.94 & 0.094 & 0.94 & 0.66 & 0.91 \\
\hline
\end{tabular}

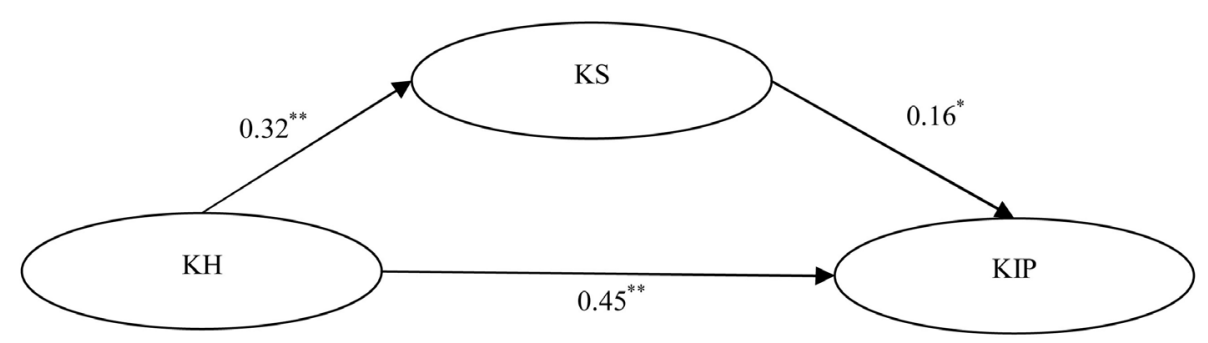

Figure 2. Structural equation model with KS as the intermediation.

lap between team members' knowledge will reduce knowledge collision and knowledge innovation. Zhang Gang emphasizes that organizations with low levels of knowledge heterogeneity are limited to knowledge of one same type will stifle innovation and improve the operational risk. All those academic supports allow us to conclude that knowledge heterogeneity is positively related to knowledge innovation performance.

2) The influences of knowledge heterogeneity on knowledge share:

As recommended individual knowledge with enough heterogeneity, complementarity and integration results in active knowledge share behavior. According to Ye Lu, Pan Hongliang and Liu Xiaonong, sharing distinctive knowledge and information with others contribute to constructing heterogeneous team. In conclusion, the positive relationship between knowledge heterogeneity and knowledge share can be supported.

3) The influences of knowledge share on knowledge innovation performance:

Tang Chaoying argues that sharing distinctive knowledge and information is conducive to knowledge collision and creative solutions due to actual situation, supporting the positive relationship between knowledge share and knowledge innovation performance.

4) The mediating role of knowledge share:

Gu Jiajun and Hu Bei (2008) [12] put forward that knowledge heterogeneity at individual level, team level as well as organization level is conducive to discovering and applying a wider range of knowledge, leading to filtering more valuable information, more efficient knowledge interaction and knowledge share, better illustration of what is happening, efficient solutions to problems and more innovation, which support the mediating role of knowledge share.

a) The mediating role of share quality:

As recommended by Wang Duanxu and some other scholars, team members' different and complementary knowledge structures cause their distinctive knowledge specialty, improving both team knowledge reserves and team innovation efficacy [13]. The shared knowledge and its tightness, direction and practicality towards team tasks are the determinants to share quality.

b) The mediating role of collaborative spirit: 
Higher knowledge heterogeneity results in more decentralized knowledge distribution. More communication and cooperation are needed to acquire different knowledge, efficiently reducing the obstacles blocking knowledge share, which is conducive to the communication of heterogeneous knowledge and appearance of knowledge innovation achievements.

c) The mediating role of Miyuki performance:

Hollingshead suggest that knowledge share makes team members realize teammates' expertise and form the habit of helping each other and acquiring knowledge from specific person which solidifies the knowledge share behavior in turn and transforms knowledge heterogeneity to knowledge innovation performance.

\subsection{Implications and Recommendations}

In sum, the paper gives implications and recommendations as follow:

1) The mediating role of share quality suggests that the improvement of share quality can realize the transformation from knowledge heterogeneity to knowledge innovation performance.

2) The mediating role of collaborative spirit recommends the necessity of initiating the concept and atmosphere of knowledge share to us to achieve the transformation from knowledge heterogeneity to knowledge innovation performance.

3) The mediating role of Miyuki performance reminds us of the importance of team members' knowledge share behavior, the operational efficiency and its effects to achieve the transformation from knowledge heterogeneity to knowledge innovation performance.

\section{References}

[1] Ni, X.D. (2010) Knowledge Heterogeneity on Team Innovation Mechanism. Enterprise Economy, 8, 57-63.

[2] Fan, Z.P. (2003) Knowledge Management. Journal of Northeastern University, 73-89.

[3] Wang, Y. (2011) Research on the Relationship between Knowledge Heterogeneity, Shared Mental Model of Knowledge Innovation and R \& D Team Performance. Journal of Nanjing University of Aeronautics and Astronautics, 3, 22-33.

[4] Zhang, G. and Li, X. (2009) Member Diversity and Team Performance: Interactive Memory System as Mediator. Science Research Management, 30, 71-80.

[5] Yang, D.L. and Shi, H.F. (2005) An Empirical Study of Factors Affecting the Project Team Knowledge Creation. Science of Science and Management, 7, 92-96.

[6] Xie,Y.P., Mao, Y.Z. and Zhang, H.M. (2011) Inter-Organizational Trust, the Impact of Network Structure and the Stock of Knowledge Innovation Performance of the Network Analysis. Science \& Technology Progress and Policy, 28, 172-176.

[7] Jiang, J. (2003) Mode of Organizational Knowledge Sharing. Group Economic Research, 3, 191-192.

[8] Jiang, R.F., Huo, G.Q., Tan, H.J. and Tan, C.J. (2007) Research Team Knowledge Innovation Performance Influencing Factors-Based on Scientific Research Institutions of the National Research, Studies in Science of Science, 25, 364-372.

[9] Lv, X.J. and Yu, W.Z. (2005) An Empirical Research on Team Mental Models. Journal of Psychological Science, 28, 180-182.

[10] Zhang, J. (2008) Analysis of Factors Affecting Enterprise Technology Alliance Knowledge Sharing. Journal of Enterprise Economic, 1, 35-37.

[11] Wang, Y. and Peng, C. (2011) Heterogeneity of Knowledge and R \& D Team Knowledge Innovation Performance: The Shared Mental Model as MedIator. Journal at Intelligence, 30, 113-116.

[12] Gu J.J. and Hu, P. (2008) Heterogeneity and Enterprise Technology Innovation Performance TMT Knowledge Structure, Occupational Background. Journal of $R$ \& D management, 20, 28-33.

[13] Wu, B. and Yan, S. (2011) Impact of Intellectual Capital on Knowledge-Based Enterprise Knowledge Innovation Performance. Journal of Qiusuo, 9, 84-86. 